\title{
De bereidheid van ziekenhuispersoneel tot deelname aan een communicatietraining
}

\author{
D. de Natris, W. Brouwers
}

\begin{abstract}
Samenvatting
Inleiding: Het langetermijndoel van longitudinale communicatietrainingsprogramma's is dat medewerkers het volgen van een communicatietraining net zo normaal gaan vinden als het volgen van bijvoorbeeld een reanimatietraining. Of een longitudinaal communicatietrainingsprogramma uiteindelijk leidt tot deze vorm van cultuurverandering is echter nog niet onderzocht. Daarom is als onderzoeksvraag gesteld: hebben ziekenhuismedewerkers die hebben deelgenomen aan de basiscursus van een longitudinaal communicatietrainingsprogramma een grotere deelnamebereidheid aan een communicatietraining dan ziekenhuismedewerkers die (nog) niet hebben deelgenomen aan een trainingsprogramma?

Methode: Om deze vraag te kunnen beantwoorden is onder het ziekenhuispersoneel van het St. Elisabeth Ziekenhuis te Tilburg een gestandaardiseerde vragenlijst verspreid. De respondenten werden onderverdeeld in twee groepen: groep A bestond uit medewerkers die al deelgenomen hadden aan de basiscursus van het trainingsprogramma; groep B bestond uit medewerkers die (nog) geen basiscursus hadden gevolgd.

Resultaten: De resultaten lieten geen significante verschillen zien wat betreft de bereidheid aan de training deel te nemen, maar wel ten aanzien van de variabele attitude. Daarnaast is de voorspellende waarde van de aspecten uit de vragenlijst onderzocht. Het bleek dat drie aspecten van belang zijn.

Discussie en conclusie: Om de deelnamebereidheid van medewerkers aan de training te stimuleren, is het belangrijk a) hen de noodzaak van de training te laten inzien, b) hen te wijzen op de gevolgen die het al dan niet deelnemen aan de cursus zal hebben voor hun werk en c) hen duidelijk te maken dat zij op basis van hun kennis en ervaring kunnen bijdragen aan het succes van de training. (Natris $D$ de, Brouwers W. De bereidheid van ziekenhuispersoneel tot deelname aan een communicatietraining. Tijdschrift voor Medisch Onderwijs 2008;27(3):120-128.)
\end{abstract}

\section{Inleiding}

Het St. Elisabeth Ziekenhuis te Tilburg heeft - gesteund door de zeer positieve resultaten van een vergelijkbaar programma dat uitgevoerd is aan de Universiteit van Maastricht - in 2005 een longitudinaal communicatietrainingsprogramma ingevoerd. Het uitgangspunt bij dit trainingsprogramma is dat ziekenhuismedewerkers al in ruime mate beschikken over communicatieve vaardigheden, maar dat deze op peil gehouden dienen te worden en dat verbetering mogelijk en wenselijk is. Het programma bestaat uit de volgende onderdelen: een basiscursus (gedurende één dag), een vervolgtraject 'trainingen op maat' (een halve dag tot één dag per training), toetsing op de werkplek, en tot slot een evaluatie van de communicatie in coaching- en jaargesprekken. Longitudinaal wil zeggen dat het om een systematisch programma gaat dat gedurende enkele maanden doorloopt, probleemgestuurd is opgesteld en 
geïntegreerd wordt met de persoonlijke ontwikkeling van de medewerkers. De onderwijsdoelen van een longitudinaal communicatietrainingsprogramma kunnen aan de hand van drie dimensies worden gedefinieerd: professioneel omgaan met werktaken, met anderen (collega's en patiënten) en met zichzelf (zelfreflectie). ${ }^{1}$

Naast deze drie directe onderwijsdoelen is het langetermijndoel van een longitudinaal communicatietrainingsprogramma te karakteriseren als een vorm van cultuurverandering. Uiteindelijk is het de bedoeling dat medewerkers het volgen van een communicatietraining net zo normaal gaan vinden als het volgen van bijvoorbeeld een reanimatietraining. Bij dit langetermijndoel wordt dus communicatie erkend als een integraal onderdeel van het competentieprofiel van alle medewerkers in de zorg. Communicatieve vaardigheden dienen dan ook net als andere vaardigheden regelmatig geoefend te worden. Of een longitudinaal communicatieprogramma uiteindelijk tot deze erkenning leidt - dat wil zeggen: kijken medewerkers anders tegen een communicatietraining aan na het volgen van de basiscursus uit het communicatietrainingsprogramma dan ze daarvoor deden? - was nog niet onderzocht. Aangezien een onderzoek, gericht op het gehele longitudinale communicatieprogramma om randvoorwaardelijke redenen te omvangrijk was, is ervoor gekozen het onderzoek te beperken tot de basiscursus die binnen het longitudinale communicatietrainingsprogramma werd gegeven.

Aan het onderzoek lag de volgende vraag ten grondslag: hebben medewerkers die hebben deelgenomen aan de basiscursus van het longitudinale trainingsprogramma een grotere bereidheid tot deelname aan een communicatietraining dan medewerkers die deze cursus (nog) niet hebben gevolgd?

\section{Methode}

Een schriftelijke vragenlijst werd ingezet om de deelnamebereidheid aan een communicatietraining van een grote groep medewerkers, in dit geval de medewerkers van het St. Elisabeth Ziekenhuis ${ }^{2}$, te achterhalen. ${ }^{3-4}$

\section{De respondenten}

De medewerkers werden naar afdeling (receptie/beveiliging, verloskamers/poli gynaecologie \& E3, neurochirurgie, urologie, orthopedie, intensive care) ingedeeld. Tevens werd een indeling gemaakt naar opleiding, leeftijd en geslacht.

Bij het St. Elisabeth Ziekenhuis zijn 2700 mensen werkzaam. Inmiddels hebben 600 medewerkers binnen het longitudinale communicatietrainingsprogramma de basiscursus en eventuele trainingen op maat gevolgd. Zij vormden de eerste groep medewerkers binnen dit onderzoek (verder te noemen: groep A). Uit deze groep van 600 medewerkers werden steekproefsgewijs 165 personen geselecteerd. Daarnaast werden 165 medewerkers geselecteerd die nog geen training binnen de organisatie hadden gevolgd; zij vormden de tweede onderzoeksgroep (groep B).

Van deze 330 personen hebben 117 personen gereageerd op de enquête (17 receptie/beveiliging; 14 verloskamers/poli gynaecologie/E3; 28 neurochirurgie; 19 urologie; 17 orthopedie; 17 intensive care; 5 anders), waarvan $49.6 \%$ (58) geen en $50.4 \%$ (59) wel een communicatietraining had gevolgd.

\section{De vragenlijsten}

Er zijn twee versies van de vragenlijst gebruikt: één versie afgestemd op groep A en één versie afgestemd op groep B (de vragenlijsten zijn op te vragen bij de auteurs). De vragenlijst is opgesteld volgens het diagnosemodel voor bereidheid tot het volgen van een communicatietraining. ${ }^{5-7}$ Daarin staan drie variabelen centraal: 
- De attitude (ofwel 'willen deelnemen aan de cursus'). Deze variabele bestaat uit de volgende vier dimensies: de perceptie van de gevolgen van cursusdeelname voor het werk van het individu, de meerwaarde die deelname oplevert voor de organisatie, de positieve en negatieve emoties die opkomen voorafgaand aan cursusdeelname en de ervaren betrokkenheid ten opzichte van cursusdeelname.

- De subjectieve norm (ofwel 'menen te moeten deelnemen aan de cursus'). Deze variabele bestaat uit de volgende twee dimensies: de ervaren noodzaak om deel te nemen aan de cursus en de houding van collega's ten opzichte van cursusdeelname.

- De eigen effectiviteit (ofwel 'menen te kunnen deelnemen aan de cursus'). Deze variabele bestaat uit de volgende vier dimensies: de ervaring met eerdere cursussen, de kwaliteit van de communicatie voorafgaand aan de cursus, de verwachte complexiteit en de timing van de cursus.

Om te controleren of deze dimensies daadwerkelijk samen het onderliggende concept 'bereidheid tot cursusdeelname' meten, werd een factoranalyse uitgevoerd. De KMO-waarden (Kaiser-MeyerOlkin criterium) lieten factoranalyse toe voor alle items, met uitzondering van die van 'timing'; deze vertoonden te weinig onderliggende samenhang om daaruit een factor te kunnen afleiden. Tevens is de factorlading berekend. Op basis van de resultaten (correlaties $>0.30$ ) kon gesteld worden dat de items voor het meten van de vier dimensies van attitude inderdaad de variabele meten. Ditzelfde gold voor de items voor het meten van de twee dimensies van de subjectieve norm. Wat betreft de eigen effectiviteit werden de vier di- mensies teruggebracht tot drie (ervaring met eerdere cursussen, communicatie voorafgaand aan de cursus en verwachte complexiteit).

Daarnaast is de betrouwbaarheid (interne consistentie) van de schalen vastgesteld. De bijbehorende statistische maat is Crombachs Alfa. De interne consistentie van de schalen was voldoende (waarden van .723 tot .798) tot goed (waarden van .807 tot .891 ). Alleen scoorde wat betreft de eigen effectiviteit de waarde voor complexiteit net geen voldoende (.676) en voor timing een onvoldoende (.402).

\section{Statistische analyse}

- Beschrijvende analyse. De antwoorden konden worden gegeven op een vijfpuntsschaal, met waarden van 1 (helemaal niet mee eens) tot 5 (helemaal mee eens). Voor een schaal op intervalniveau kunnen gemiddelden en standaarddeviaties worden berekend.

- Toetsende analyse. Om de representativiteit en de statistische significantie te kunnen bepalen is een Chi-kwadraat toets voor de aspecten geslacht, leeftijd en afdeling toegepast. Uit de analyses voor zowel geslacht, leeftijd als afdeling van de respondenten bleek dat de resultaten uit de steekproef representatief waren voor de gehele populatie. Omdat ook onderzocht moest worden of er verschillen zijn te onderscheiden tussen de verschillende groepen medewerkers, en of deze verschillen al dan niet op toeval berustten, zijn t-toetsen en F-toetsen gebruikt. Ten slotte is een regressieanalyse uitgevoerd. Op basis van deze analyse kon worden nagegaan welke van de variabelen en dimensies uit het onderzoek de beste voorspellers zijn van de bereidheid van de medewerkers aan een communicatietraining deel te nemen. 


\section{Resultaten}

\section{Attitude}

Groep A keek positiever tegen het trainingsprogramma aan dan groep B. Op de dimensies 'emoties' en 'betrokkenheid' scoorde groep A statistisch significant hoger (tabel 1).

Geslacht, leeftijd en opleidingsniveau bleken niet significant van invloed te zijn op de attitude van medewerkers ten aanzien van het trainen van communicatieve vaardigheden. De afdeling waar medewerkers werkzaam zijn bleek wel bepalend te zijn voor de attitude. Zo zien medewerkers van de afdeling receptie/beveiliging in significant hogere mate de meerwaarde in van de communicatietraining dan medewerkers van de afdelingen gynaecologie, neurochirurgie en orthopedie $(\mathrm{p}<0.005)$. Daarnaast is de groep medewerkers van de afdeling receptie/beveiliging sterker betrokken bij de communicatietraining dan de medewerkers van de afdelingen orthopedie en intensive care $(\mathrm{p}<0.01)$. Ove- rigens zien op een enkeling na alle respondenten de meerwaarde van een communicatietraining in.

\section{Subjectieve norm}

In dit onderzoek werden tussen de twee groepen medewerkers geen significante verschillen gevonden wat betreft de subjectieve norm. Wel bleken de gemiddelden op de dimensie 'noodzaak' iets verder uit elkaar te liggen dan de gemiddelden op de dimensie 'houding collega's' (tabel 2). Beide groepen medewerkers (degenen die wel versus degenen die niet een cursus hebben gevolgd) kijken dus licht positief tegen het moeten veranderen aan. Geslacht, afdeling en opleidingsniveau bleken niet van invloed te zijn op de 'ervaren noodzaak' en 'houding van collega's' ten aanzien van de communicatietraining. Wat betreft de leeftijd werden wel significante verschillen gevonden. De jongste leeftijdsgroep ( $<24$ jaar) bleek communicatietraining significant 'noodzakelijker' te vinden dan medewerkers met een leeftijd $>24$ jaar $(\mathrm{F}=6.080, \mathrm{p}<0.01)$.

Tabel 1. De scores met betrekking tot de dimensies 'emoties' en 'betrokkenheid' in de groepen met en zonder

\begin{tabular}{llcccc}
\multicolumn{1}{c}{ training. } & & & & \\
\hline & Groep & Aantal & Gemiddelde & SD & \\
\hline \multirow{2}{*}{ Emoties } & training & 59 & 3.77 & .41 & \multirow{2}{*}{$\mathrm{t}=2.282, \mathrm{p}<0.05$} \\
& geen training & 57 & 3.55 & .59 & \\
\multirow{3}{*}{ Betrokkenheid } & training & 59 & 3.11 & .66 & $\mathrm{t}=2.970, \mathrm{p}<0.01$ \\
& geen training & 56 & 2.73 & .73 & \\
& & & & &
\end{tabular}

Tabel 2. De scores met betrekking tot de dimensies 'noodzaak' en 'houding collega's' in de groepen met en

\begin{tabular}{llcccc}
\multicolumn{2}{c}{ zonder training. } & & & \\
\hline \multirow{2}{*}{ Noodzaak } & Groep & Aantal & Gemiddelde & SD & \\
\multirow{4}{*}{ Houding collega's } & training & 59 & 3.32 & .72 & n.s. \\
& geen training & 56 & 3.07 & .75 & \\
& training & 59 & 3.45 & .63 & n.s. \\
& geen training & 56 & 3.39 & .55 & \\
\hline
\end{tabular}




\section{Eigen effectiviteit}

Aangezien bij de dimensie 'communicatie' de ervaren communicatie voorafgaand aan de cursus over bijvoorbeeld de planning werd onderzocht, kon deze dimensie alleen aan groep A worden voorgelegd. Daarom werden ten aanzien van 'de eigen effectiviteit' alleen de verschillen met betrekking tot de dimensies 'ervaring met eerdere cursussen' en 'complexiteit' onderzocht.

De dimensie 'ervaring' liet een iets hogere gemiddelde score zien voor groep A, maar dit was niet significant hoger (tabel 3). De dimensie 'complexiteit' liet wel een duidelijk significant verschil zien. Groep A scoorde hierbij hoger, hetgeen betekent dat de cursus complexer was dan van tevoren door de cursisten werd verwacht (tabel 3).

Geslacht, leeftijd en afdeling waren niet van invloed op de scores op de dimensies 'ervaring' en 'complexiteit'. Het opleidingsniveau bleek wel significant bepalend voor de bijdrage die mensen denken te kunnen leveren aan het succes van de communicatietraining. Echter, het verschil dat werd gevonden is niet het verschil dat werd verwacht. Medewerkers met een opleiding op LBO-niveau verwachtten namelijk dat ze een significant hogere bijdrage kunnen leveren aan het succes van de communicatietraining dan medewerkers met het opleidingsniveau HAVO en MBO ( $\mathrm{p}=0.007)$.

\section{Bereidheid tot deelname aan de communicatietraining}

De vraag of deelname aan een longitudinaal communicatietrainingsprogramma daadwerkelijk leidt tot attitudeverandering en bereidheid op het gebied van trainingen, kan dus niet eenduidig worden beantwoord. Enerzijds leidt training wel tot een betere attitude, anderzijds komt in dit onderzoek niet naar voren dat er sprake is van impact op het gebied van de subjectieve norm en de eigen effectiviteit. Aangezien de subjectieve norm gelijk blijft en de eigen effectiviteit alleen significante scores laat zien voor de dimensie 'complexiteit', is geen invloed vastgesteld van de communicatietraining op de mate waarin medewerkers overtuigd zijn dat ze 'moeten' en 'kunnen' veranderen. Er kan in deze slechts worden gesteld dat medewerkers de communicatietraining vooraf te licht inschatten. Verder blijven alle scores op de dimensies voor subjectieve norm en eigen effectiviteit licht positief, wat aangeeft dat medewerkers zowel voor als na het volgen van de communicatietraining de 'noodzaak' en de 'mogelijkheid' tot deelname inzien.

\section{Voorspellers van bereidheid}

Aan de hand van een regressieanalyse werd allereerst nagegaan of er een rechtlijnig verband kon worden gevonden tussen de volgende drie dimensies:

- Gevolgen van de cursus voor het werk, meerwaarde van deelname voor de or-

Tabel 3. De scores met betrekking tot de dimensies 'ervaring' en 'complexiteit' in de groepen met en zonder eerdere training.

\begin{tabular}{llcccc}
\hline & Groep & Aantal & Gemiddelde & SD & \\
\hline \multirow{2}{*}{ Ervaring } & training & 59 & 3.3559 & .66340 & n.s. \\
& geen training & 56 & 3.1146 & .66772 & \\
Complexiteit & training & 59 & 3.2847 & .58252 & $\mathrm{t}=2.845, \mathrm{p}<0.01$ \\
& geen training & 56 & 3.0095 & .44936 & \\
\hline
\end{tabular}


ganisatie, ervaren emoties voorafgaand aan de cursus en ervaren betrokkenheid bij de cursus (samen de variabele 'attitude').

- Ervaren noodzaak om aan de cursus deel te nemen en de houding van collega's ten opzichte van de cursus (samen de variabele 'subjectieve norm').

- Ervaring met cursussen en verwachte complexiteit van de cursus (samen de variabele 'eigen effectiviteit') enerzijds en de bereidheid van de medewerkers anderzijds.

Drie aspecten blijken de bereidheid tot deelname aan de training voor 52\% te voorspellen:

- De dimensie 'noodzaak' is de beste voorspeller voor de bereidheid $(\mathrm{p}<0.001)$. Deze blijkt voor $37 \%$ de variantie te verklaren.

- De dimensie 'gevolgen werk' levert eveneens een bijdrage aan de voorspelling van de bereidheid $(\mathrm{p}<0.001)$. De twee dimensies samen verklaren $49 \%$ van de variantie.

- De dimensie 'ervaring' ( $\mathrm{p}<0.05)$. Wanneer deze dimensie wordt meegenomen, wordt $52 \%$ van de variantie verklaard.

De overige dimensies blijken geen significante bijdrage te leveren aan de voorspelling van de bereidheid van de medewerkers.

Uit de regressieanalyse voor groep B bleek opnieuw dat de dimensies 'noodzaak' en 'gevolgen werk' de beste voorspellers waren voor de bereidheid van de medewerkers. De dimensie 'noodzaak' verklaart $40 \%$, de twee dimensies samen verklaren $56 \%$ van de variantie. De derde dimensie die bepalend was voor de voorspelling van de bereidheid bleek voor deze groep echter niet 'ervaring' te zijn, maar 'emoties'. Ook voor groep B bleken dus het inzien van 'de noodzaak' en de 'positieve gevolgen van de training voor het werk' van belang voor de bereidheid, maar ook hun 'emoties' bleken hierop van invloed te zijn.

Voor groep A waren eveneens de dimensies 'noodzaak' en 'gevolgen werk' het meest bepalend voor de bereidheid. Met de dimensie 'noodzaak' kon 32\% van de variantie worden voorspeld, met beide dimensies $41 \%$. De derde dimensie die een sterke voorspeller was voor de veranderingsbereidheid, was de dimensie 'houding collega's'. Wanneer deze dimensie wordt toegevoegd, wordt $45 \%$ van de variantie verklaard.

Deze resultaten houden in dat als medewerkers de 'noodzaak van de communicatietraining' en de 'positieve gevolgen hiervan voor hun werk' inzien, waarbij hun 'collega's een positieve houding ten opzichte van de communicatietraining' hebben, de bereidheid aan de communicatietraining deel te nemen zal toenemen.

\section{Discussie en conclusie}

In dit onderzoek werd nagegaan of medewerkers die hebben deelgenomen aan de basiscursus van een longitudinaal communicatietrainingsprogramma een grotere bereidheid tonen tot het deelnemen aan een communicatietraining dan medewerkers die deze cursus (nog) niet hebben gevolgd. Op grond van deze studie kan een model worden opgesteld met de dimensies die het meest van belang zijn voor het voorspellen van de bereidheid van medewerkers tot deelname aan een communicatietraining.

Allereerst zal het model worden weergegeven zoals dat is gevonden voor de gehele steekproef. Vervolgens zal voor de beide groepen medewerkers worden aangegeven wat de belangrijkste dimensies zijn in het bepalen van de bereidheid, in dit geval de acceptatie van de communicatietraining.

Uit de resultaten blijkt dat de dimensies 'noodzaak' en 'gevolgen werk' niet alleen voor de beide groepen samen (figuur 1) 
maar ook wanneer de groepen apart worden bekeken (figuur 2) de grootste voorspellende waarde hebben voor de veranderingsbereidheid. Het verschil tussen de beide groepen betrof de derde dimensie. Voor de groep medewerkers zonder communicatietraining bleek dit de dimensie 'emoties' te zijn, voor de groep met communicatietraining de dimensie 'houding collega's' (figuur 2).

In dit onderzoek zijn ten aanzien van de variabele attitude significante verschillen gevonden tussen medewerkers die een communicatietraining hebben gevolgd en medewerkers die (nog) geen communicatietraining hebben gevolgd. De medewerkers van groep A kijken positiever aan tegen de communicatietraining dan de medewerkers uit groep B. Het gegeven dat medewerkers een positievere attitude hebben na het volgen van de training, kan worden veroorzaakt door negatieve ervaringen met eerdere trainingen. Daardoor zouden ze voorafgaand aan de communicatietraining kunnen verwachten dat het 'weer zo'n soort training' zou gaan worden als andere trainingen waarmee ze slechte ervaringen hebben. Deze verklaring wordt ondersteund door de voorspellende waarde van de dimensie 'ervaring', hetgeen aangeeft dat eerdere ervaringen van medewerkers een rol spelen bij de acceptatie van de communicatietraining.

Wat betreft de demografische kenmerken blijkt de afdeling waar medewerkers werkzaam zijn invloed te hebben op de bereidheid een training te volgen. Interessant is de constatering dat medewerkers van de afdeling receptie/beveiliging zich sterker betrokken voelen bij de communicatietraining dan medewerkers van de afdeling orthopedie en intensive care. Verder zien de medewerkers van receptie/beveiliging ook de meerwaarde van de communicatietraining in hogere mate in dan medewerkers van de afdelingen gynaecologie,

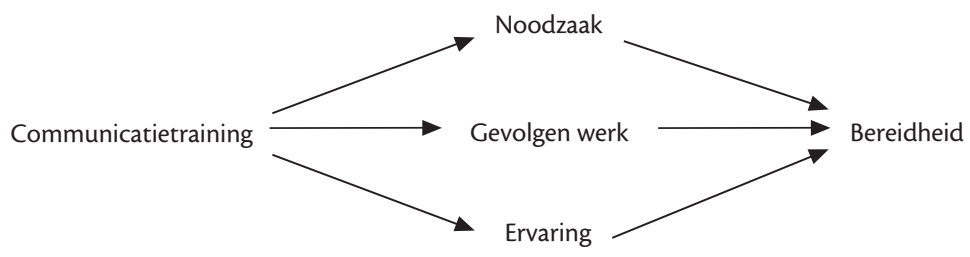

Figuur 1. De relatie tussen communicatietraining, gevolgen werk, noodzaak, ervaring en bereidheid.
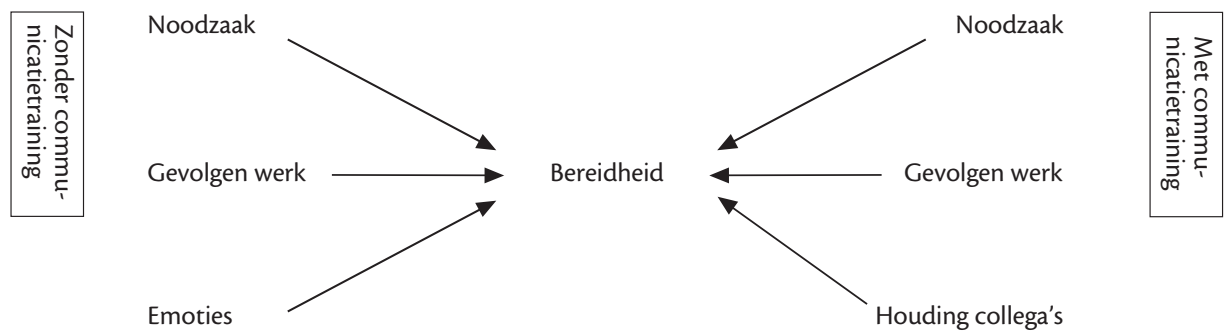

Figuur 2. Dimensies met de hoogste verklarende waarde voor de bereidheid, uitgesplitst naar de groepen zonder communicatietraining en met communicatietraining. 
neurochirurgie en (opnieuw) orthopedie. Deze resultaten kunnen worden verklaard uit het feit dat de kerntaak van receptie en beveiliging meer raakvlakken heeft met communicatie dan de kerntaak van de overige afdelingen.

De jongste leeftijdsgroep ( $<24$ jaar) ziet significant sterker de noodzaak van een communicatietraining in dan oudere medewerkers. Dit kan worden verklaard uit het feit dat communicatieve vaardigheden in hedendaagse opleidingen meer nadruk krijgen dan enkele (of tientallen) jaren geleden. Bovendien is het tegenwoordig van belang dat medewerkers voortdurend worden bijgeschoold. Jongere medewerkers zijn dan ook in deze kenniseconomie opgegroeid en aan deze manier van werken gewend. Oudere medewerkers zijn meer gewend aan het volgen van een eenmalige opleiding voor het vak waarna kan worden gewerkt. Opleiding hoort voor hen bij het traject dat aan het werk voorafgaat en is niet een steeds terugkerende factor.

Op de variabele 'kunnen' werd een significant verschil gevonden wat betreft de dimensie 'complexiteit'. Groep A scoorde hierop hoger dan groep B, hetgeen aangeeft dat de cursus complexer is dan van tevoren was verwacht. Overigens kan dit ook hebben bijgedragen aan het positievere beeld dat medewerkers van de communicatietraining hebben na het volgen ervan. Wanneer ze namelijk bij aanvang verwachtten dat het een cursus zou zijn met weinig inhoud, waarvan ze weinig konden leren, kijken ze er ook niet positief tegenaan. Wanneer dan achteraf blijkt dat ze wel van de communicatietraining hebben geleerd, zal dat bijdragen aan een positiever beeld. Of deze verklaringen voor de gevonden verschillen juist zijn, zou in een vervolgonderzoek kunnen worden nagegaan. In bijvoorbeeld diepte-interviews zou medewerkers gevraagd kunnen worden naar de motieven en gedachten bij de antwoorden op de vragenlijst.

Om de relaties te onderzoeken had een ruime onderzoekspopulatie uit meer ziekenhuizen een representatief beeld kunnen leveren voor alle ziekenhuizen in Nederland. Echter, gezien de randvoorwaarden viel een vragenlijstonderzoek van deze omvang niet binnen de mogelijkheden en werd voor het onderzoek ingezoomd op het St. Elisabeth Ziekenhuis. Wel had het vragenlijstonderzoek met 117 respondenten een redelijk grote omvang, waardoor de verkregen resultaten voor de gehele organisatie een betrouwbaar beeld opleveren.

\section{Literatuur}

1. Verkerk MA, Bree M de, Jaspers Fr. Reflectieve professionaliteit. Naar een invulling van het CCMS-competentiegebied 'professionaliteit'. Tijdschrift voor medisch onderwijs 2005;24(4):162-7. [Reflective professionalism. Towards an interpretation of 'professionalism' as defined by the Central College of Medical Specialisms (CCMS) Dutch Journal of Medical Education 2005;24(4): 162-7].

2. Opleidings- en OnderzoeksCentrum St. Elisabeth Ziekenhuis. Communicatietrainingen in het EZ: Longitudinaal communicatie vaardigheidsonderwijs. Tilburg: 2005. [Communication training in St. Elisabeth Hospital: A longitudinal communication training programme. Tilburg: 2005].

3. Kraut A. Organizational surveys. San Francisco: Jossy-Bass Inc. Publishers; 1996.

4. Korzilius H. De kern van survey-onderzoek Assen: van Gorcum; 2000. [The essentials of survey research. Assen: van Gorcum; 2000].

5. Metselaar, EE. Ongepubliceerde vragenlijst voor het meten van de bereidheid tot het volgen van communicatietrainingen. Driebergen: Academic Consultancy Services (ACS); z.j. [An Unpublished questionnaire to ivestigate the willingness to participate in communication training. Academic Consultancy Services (ACS); z.j.].

6. Metselaar EE. Assessing the Willingless to change; Construction and validation of the DINAMO [dissertation]. Amsterdam: VU-huisdrukkerij; 1997.

7. Metselaar EE, Cozijnsen AJ. Van weerstand naar veranderingsbereidheid; over willen, moeten en kunnen veranderen. Heemstede: Holland Business Publications; 2002. [From resistance to willingness to change; the willingness, the necessity and the ability to change. Heemstede: Holland Business Publications; 2002] 
De auteurs:

Drs. Dirk de Natris is als medewerker verbonden aan de opleiding Bedrijfscommunicatie van de Radboud Universiteit van Nijmegen.

Mw. drs. Wendy Brouwers is in 2006 afgestudeerd aan de opleiding Bedrijfscommunicatie van de $R U$ van Nijmegen.

\begin{abstract}
Correspondentieadres:
Drs. D. de Natris, Radboud Universiteit Nijmegen, afdeling Communicatie en Informatiewetenschappen/ Bedrijfscommunicatie, Erasmusplein 1, postbus 9103, 6525 HT Nijmegen.Tel. werk: 024-3615719; tel. privé: 024-3229505; e-mail: h.denatris@let.ru.nl Privé-adres: Gerard Noodtstraat 13, 6511SV Nijmegen.
\end{abstract}

Belangenconflict: geen gemeld.

Financiële ondersteuning: geen gemeld.

\section{Summary}

Introduction: The long term goal of longitudinal communication training programmes is to make participation in communication training just as normal for staff members as participation in, for example, training in resuscitation. Because no studies have examined whether this is achievable, we investigated whether hospital staff who had participated in the basic course of a longitudinal communication training programme showed greater willingness to participate in further communication training compared to hospital staff who had not (yet) participated in the communication training programme.

Method: A standardised questionnaire was administered to staff members of St. Elisabeth Hospital, Tilburg. The respondents were divided into two groups: one group who had and one group who had not (yet) participated in the basic communication course.

Results: The results showed no significant differences between the two groups in willingness to participate in communication training. We also examined the predictive value for willingness to participate in training of the different aspects included in the questionnaire.

Discussion and conclusion: In order to stimulate the willingness of the staff to participate in the training, three aspects turned out to be relevant: a] to increase awareness of the necessity to participate in communication training; $b]$ to point out to staff members what consequences their decision to participate in the course or not would have for their job; c] to make it clear to staff members that they can contribute tot the success of communication training, based upon their knowledge and experience. (De Natris D, Brouwers W. The willingness of hospital staff to participate in communication training. Dutch Journal of Medical Education 2008;27(3):120-128.) 